\title{
Pressure Dependent Kinetics of Magnesium Oxide Carbothermal Reduction
}

\author{
Boris A. Chubukov, Aaron W. Palumbo, Scott C. Rowe, Illias Hischier, Arto J. Groehn, Alan W. Weimer* \\ Department of Chemical and Biological Engineering, University of Colorado Boulder, 596 UCB, Boulder, Colorado \\ 80309-0596, USA \\ *alan.weimer@colorado.edu
}

\begin{abstract}
The rate of $\mathrm{MgO}$ carbothermal reduction was studied at temperatures from $1350-1650^{\circ} \mathrm{C}$ and pressures from $0.1-100 \mathrm{kPa}$ based on product gas analysis at near isothermal conditions. For all temperatures the initial rate of carbothermal reduction increased inversely with pressure, and between conversions of $20-35 \%$ a transition occurred after which the reaction rate was maximum at $10 \mathrm{kPa}$. Analysis of reacted pellets showed that the reaction stoichiometry, the ratio of $\mathrm{C}$ to $\mathrm{MgO}$ reacted, was less than unity and decreased with pressure indicating $\mathrm{CO}_{2}$ generation was more prevalent at elevated pressures. SEM imaging revealed the dissolution of $\mathrm{C}$ and $\mathrm{MgO}$ contact with conversion, andisoconversional analysis points to a change inthe rate determining step between 1 and 10kPa. The given experimental observations argue the importance of mass transfer and gaseous intermediates. A kinetic model is formulated based on a macroscopic species balance with $\mathrm{CO}_{2}$ as the reaction intermediate.
\end{abstract}

Keywords

Carbothermal reduction;isoconversional; model-free; kinetics;

\section{Introduction}

Production of magnesium metal by carbothermal reduction of magnesium ore (namely magnesia and dolomite) is an attractive alternative to reduction by ferrosilicon ( $42 \mathrm{~kg} \mathrm{CO}{ }_{2 \text { eq }} / \mathrm{kg} \mathrm{Mg}$ [1]) or electrolysis of $\mathrm{MgCl}_{2}\left(\sim 24 \mathrm{~kg} \mathrm{CO} \mathrm{CO}_{2 \mathrm{q}} / \mathrm{kg} \mathrm{Mg}\right.$ [1]) due to its potentiallower energy requirements and greenhouse gas emissions[2, 3]. Harnessing solar thermal radiation to provide some or all of the energy required for reduction has been proposed as a method to further lower GHG emissions[4]. In general, the carbothermal reduction reaction is written as,

$$
M O_{x}+C \rightarrow M O_{x-1}+C O
$$

andhas been studied for a variety of metal oxides. Reaction (1) is highly endothermic and results in a large entropy increase due to the generation of gases from solids. Operating under vacuum, or usinginert gas for dilution, increases the thermodynamic favorability of the reactionsuch that the process can operate at lower temperatures, and has been shown experimentally to increase the reaction rate [5-8]. The generation of $\mathrm{CO}_{2}$ as a gaseous intermediate has been proposed as a mechanism since $1875[9]$ and is described by reactions( 2 ) and (3). 


$$
\begin{gathered}
\mathrm{MO}_{x}+\mathrm{CO} \rightarrow \mathrm{MO}_{x-1}+\mathrm{CO}_{2} \\
\mathrm{C}+\mathrm{CO}_{2} \rightarrow 2 \mathrm{CO}
\end{gathered}
$$

Other mechanisms, such as reaction through gaseous carbides[10] and hydrogen[11]intermediates as well as by the thermal dissociation of the metal oxide[12], have been proposed. The presence of $\mathrm{CO}_{2}$ in the gaseous products [13-16] and an extent of reaction that exceeds the stoichiometric limit of reaction (1) [14] supports the mechanism described by reactions (2) and (3).Reaction (3) is considered by some $[14,15,17,18]$ to be the rate limiting step of carbothermal reduction due to the measured activation energy for the overall reaction being similar to that of carbon gasification ( $200 \mathrm{~kJ} / \mathrm{mol})[19-23]$ and due to experiments showing that catalysts used for carbon gasification also increase the rate of carbothermal reduction[15, 24]. The sum of reactions (1)-(3) is,

$$
M O_{x}+\lambda C \rightarrow M O_{x-1}+(2 \lambda-1) C O+(1-\lambda) \mathrm{CO}_{2}
$$

where $\lambda$ is the reaction stoichiometrythat relates the extent of carbon oxidation to metal oxide reduction.

47

The rate of $\mathrm{MgO}$ carbothermal reduction has been measured by thermogravimetry[4, 6-8, 18, 25-28]and product gas analysis[29]using resistive, solar, and inductive heating.Since the rate of heating to the reaction temperatureis finite and strongly depends on the heating methods, high-temperature kinetic measurements are inherently non-isothermal. For carbothermal reduction, the contributions of reactions (1)-(3), the continually changing particle morphology, and the mass transfer of product gases out of the pellet or powder mixture results in the heating rate having a large effect on the measured rate of reaction. Thermogravimetric measurements have been carried out with fast heating rates using custom solar TG instruments where the pellet or powder mixture was exposed directly to concentrated radiation or indirectly through a heated wall[7, 30]. The concentrated radiation heats from one direction resulting in a temperature gradientwithin the pellet or powder mixture complicating kinetic analysis[31]. In this study, fast heating rates were achieved by dropping reactant pellets into a hot furnace.

The experimental space for previous $\mathrm{MgO}$ carbothermal reductionstudies and this work is shown in Figure 1.Previous investigations encompass a wide range of experimental conditions; however kinetic

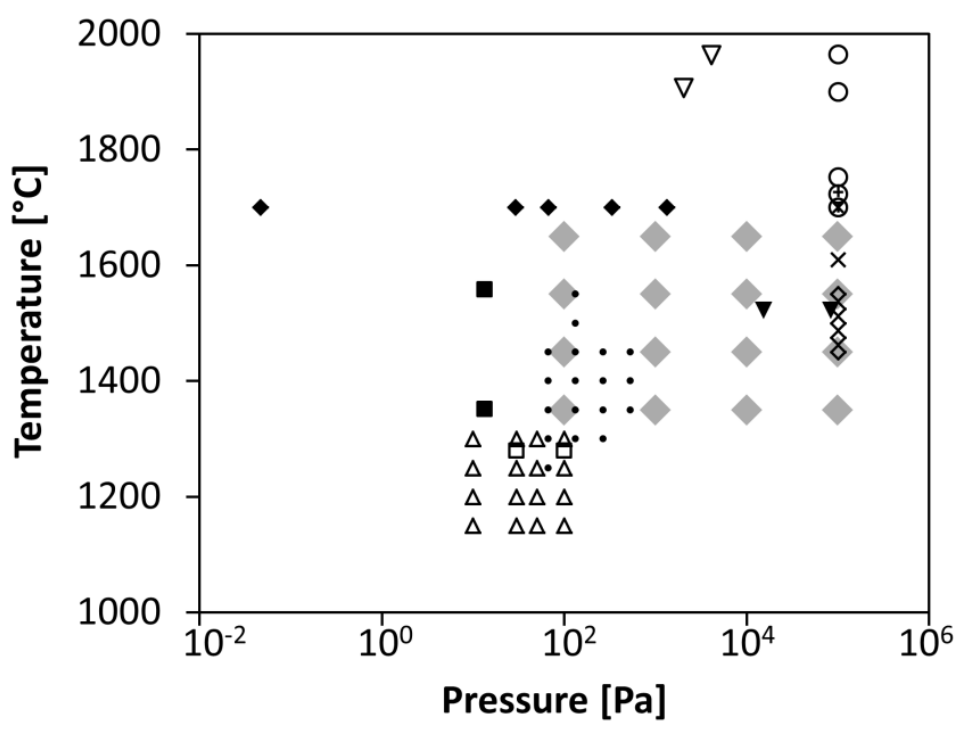

V Levêque and Abanades (2015)

$\square$ Yang et al. (2012)

$\Delta$ Xie et al. (2013)

$\times$ Rongti et al (2002)

* Rongti et al (2002)

$\nabla$ Murray et al. (1995)

+ Hong et al. (2003)

$\diamond$ Gálvez et al (2008)

o Prentice and Nagle (2009)

- Gulyanitzkii and Chizhikov (1955)

- Khazanov (1959)

- Komarek et al. (1963)

- This Work

Figure 1. Experimental space for studies of $\mathrm{MgO}$ carbothermal reduction, including this work 
modeling exists exclusively through simple solid-state kinetic expressions[32] dependent only on temperature and conversion which do not take into account the immense effect of pressure on kinetics. In this work, the rate of $\mathrm{MgO}$ carbothermal reduction was calculated by product gas analysis at temperatures from 1350 to $1650^{\circ} \mathrm{C}$ under near isothermal conditionsand pressures from 0.1 to $100 \mathrm{kPa}$ using a $2^{4}$ experimental design.A macroscopic species balance within a single pellet based on reactions (1)-(3)wasformulated to continuously predict the reduction rate as a function of temperature, pressure, gas velocity, and conversion.

\section{Thermodynamics}

The thermodynamic favorability of reaction (1) can be represented by an Ellingham diagram. The Gibbs free energy change for $\mathrm{Mg}$ and $\mathrm{C}$ oxidation at product gas pressures of 1 and 100kPaare shown in Figure 2. Once $\Delta G_{f}^{0}$ is more negative for carbon oxidation than $\mathrm{Mg}$ oxidation, reaction (1)is favored to proceed in the forward direction. The change in $\Delta G_{f}^{0}$ with temperature for the half-reactions is primarily due to the change in entropy from the generation ( $C$ oxidation) or consumption ( $\mathrm{Mg}$ oxidation) of gases. Lowering the partial pressure of product gases shifts the equilibrium such that reaction(1) is favored at lower temperatures. Based on Figure 2, reaction (1)is thermodynamically favored at 1350 and $1767^{\circ} \mathrm{C}$ for product gas pressures of 1 and $100 \mathrm{kPa}$, respectively. For a detailed discussion on the thermodynamics of carbothermal reduction the

Temperature $\left[{ }^{\circ} \mathrm{C}\right]$

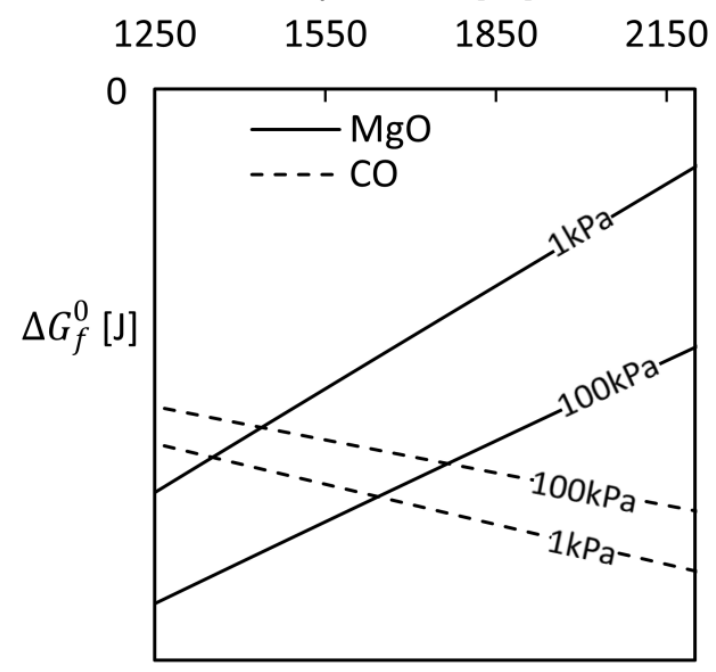

Figure 2. Ellingham Diagram for $\mathrm{CO}$ and $\mathrm{MgO}$ reader is referred to Halmann et al. (2011)[33].

\section{Methods \& Materials}

\subsection{Materials and Pelletization}

Magnesium oxide $\left(D_{p}=10 \mu \mathrm{m}\right)$ was obtained from Martin Marietta (MagOx Super Premium). Chevron Ace carbon black $\left(D_{p}=42 \mathrm{~nm}\right)$ was used as the carbon source, andPAYGEL ${ }^{\circledR} 290$ pregelatinized wheat starch from ADM was used as a binder.

Carbon and magnesium oxide were mixed in a molar ratio of $2.0(\mathrm{C} / \mathrm{MgO})$ followed by the addition of $10 w t \%$ starch. Water was added to create a paste which was then pressed into $6.35 \mathrm{~mm}$ spherical molds. The pellets were dried at $105^{\circ} \mathrm{C}$ in air for 12 hours and then pyrolyzedfor 2 hours at $650^{\circ} \mathrm{C}$ in $\mathrm{N}_{2}$. After pyrolysis, the final $\mathrm{C} / \mathrm{MgO}$ molar ratio was 2.19 due to decomposition of starch binder, and the pellets shrunk to $5.5 \mathrm{~mm}$ in diameter. 
The carbothermal reductionexperiments were carried out using argon carrier gas in a sintered $\mathrm{SiC}$ crucible (Saint Gobain, $66 \mathrm{~cm}$ long, $I D=7.5 \mathrm{~cm}$ )that was heatedwithin a graphite furnace. A schematic of the reactor setup is shown in Figure $3 . A 35 \mathrm{~cm}$ long graphite insertwith two $2.5 \mathrm{~cm}$ diameter openings directed the gas flow through the crucible. The exit line in the graphite insert was lined with a removable graphite foil for the collection of condensable reaction products after which a paper filter was used for the collection of entrained particles. The reaction temperature was measured $1 \mathrm{~cm}$ from the bottom of the crucible with a C-type thermocouple. Pressure in the system wasmeasured with an MKS Baratron absolute pressure transducer (Type 626) and was controlled with an MKS throttle valve (Model T3BIB). The concentrations of the volatile reaction products $\left(\mathrm{CO}, \mathrm{CO}_{2}\right)$ were

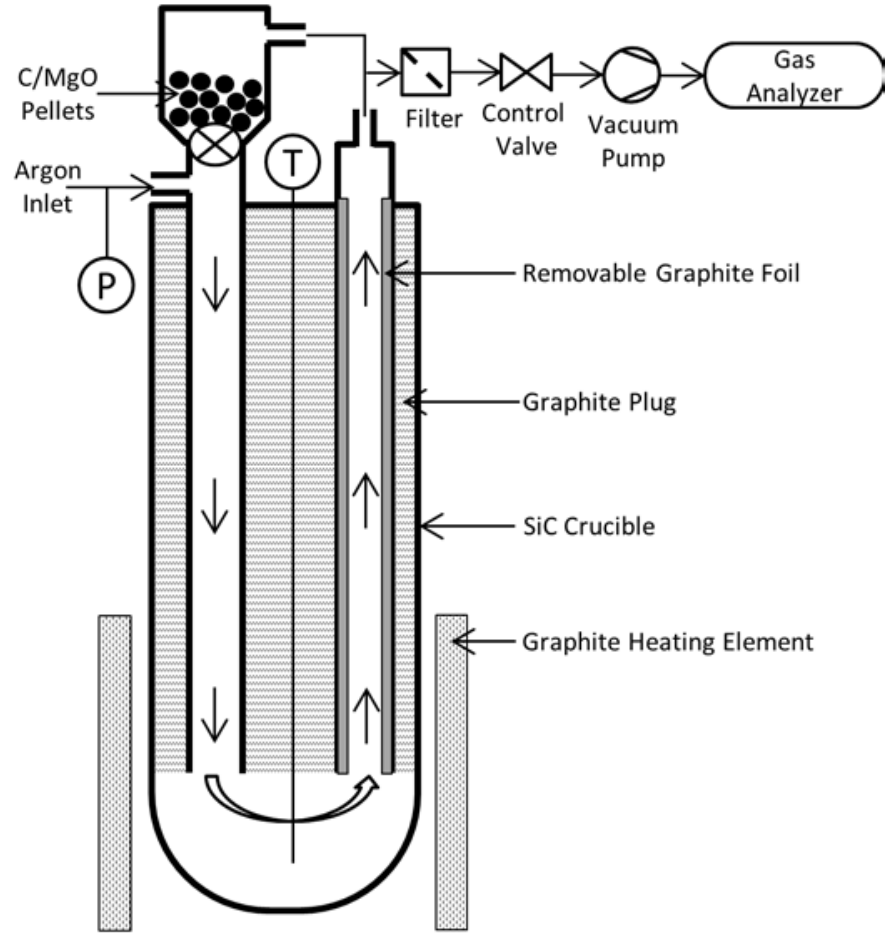

Figure 3. Reactor schematic measured with an NDIR gas analyzer (Nova $7905 \mathrm{AH}$ ) in the exhaust of a dry vacuum pump(Adixen Alcatel ACP15).

Pellets were loaded in a hopper above the crucible, separated from the hot zone by a ball valve, and the furnace was heatedto the reaction temperature.Once temperature and pressure reached steady state at the desired reaction conditions, the ball valve holding $\mathrm{C} / \mathrm{MgO}$ pellets was opened allowing pellets to fall into the hot crucible. 15 pellets $(\approx 1 \mathrm{~g})$ were dropped in each experiment. The change in pressure due to the generation of gases from reaction was adequately controlled using the throttle valve. The reaction was observed until product gases were no longer detectable ( $<0.005$ vol\%).

The flow rate of argon carrier gas was adjusted such that the velocity through the graphite insert was $3.2 \mathrm{~m} \cdot \mathrm{s}^{-1}$ for measurements at $0.1,1$ and $10 \mathrm{kPa}$ and $0.32 \mathrm{~m} \cdot \mathrm{s}^{-1}$ at $100 \mathrm{kPa}$. Higher flow rates at $100 \mathrm{kPa}$ resulted in the formation of fine $\mathrm{Mg}_{(\mathrm{s})}$ particles through homogenous condensation that clogged the particle filter at the reactor exit resulting in an uncontrollable increase of system pressure. The Reynolds number through the openings of the graphite insert varied between 1.83 and 202due to the change in gas density with pressure.

\subsection{Analytical Characterization and Compositional Analysis}

Elemental carbon and oxygen composition in pellets before and after reactionwas determined by IR detection of $\mathrm{CO}$ and $\mathrm{CO}_{2}$ from oxidation by $\mathrm{O}_{2}$ using acombustion analyzer (LECO C200) and by reduction 
where $\beta$ is the reversion coefficientassuming a total reaction order of 1 for reversion[29].

Dispersion of the reaction products due to the void space in the reactor affected the concentration measurements in the effluent (Figure 4). This effect wasquantified with a tracer gasand corrected for using an nCSTR based dispersion model[34, 35] (Appendix D). Time dependent conversionwas calculated fromthe effluent gas composition corrected for reversion by assuming that a constant fraction of $\mathrm{Mg}_{(\mathrm{v})}$ generated reverted to $\mathrm{MgO}$,

$$
\alpha(t)=\beta \cdot \frac{\int_{0}^{t}\left(\dot{N}_{C O}+2 \dot{N}_{\mathrm{CO}_{2}}\right) d t}{N_{M g O_{\text {Initial }}}}
$$

$$
\begin{aligned}
& \alpha=\frac{N_{M g o, \text { Initial }}-N_{M g o, \text { Final }}}{N_{M g O, \text { Initial }}} \\
& Y=\frac{\int_{0}^{t, f i n a l}\left(\dot{N}_{C O}+2 \dot{N}_{C_{2}}\right) d t}{N_{M g O, \text { Initial }}-N_{M g O, \text { Final }}}
\end{aligned}
$$

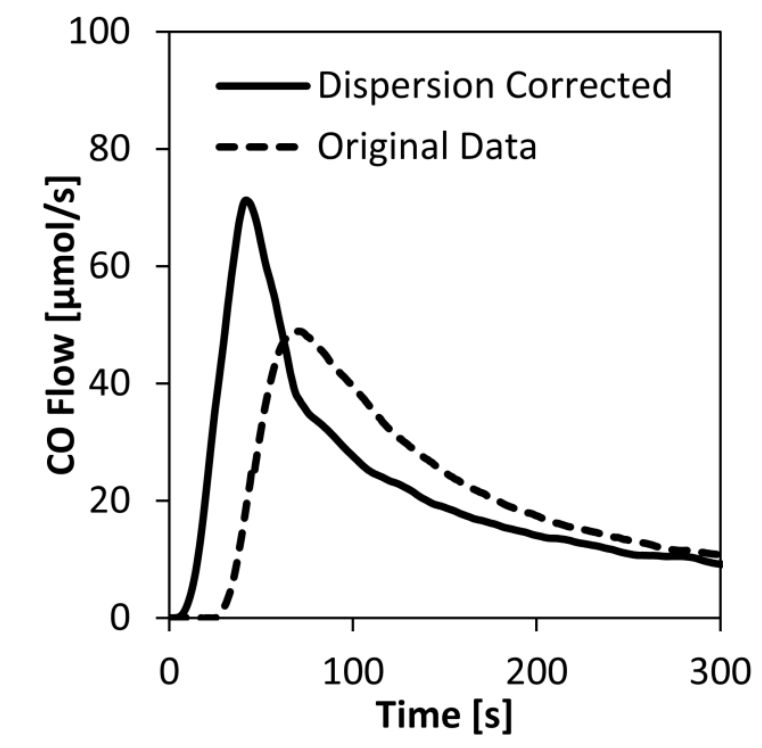

Figure 4. Dispersion correction for carbothermal reduction at $\mathrm{T}=1650^{\circ} \mathrm{C}$ and $\mathrm{P}=1 \mathrm{kPa}$

$$
\beta=1 / Y
$$

154 The reaction stoichiometry, defined by reaction (4), was calculated from the composition of the reacted 155 pellets.

$$
\lambda=\frac{N_{C, \text { Initial }}-N_{C, \text { Final }}}{N_{M \text { go,Initial }}-N_{M g O, \text { Final }}}
$$

156 The maximum absolute difference in duplicate experiments was $0.88 \%$ conversion at any given time 157 point, and the overall mass balance for each experiment was closed to within $10 \%$.

\section{$\underline{\text { 4. Results and Discussion }}$}


Carbothermal reduction experiments, as described in section 3,are assumed to be isothermal. An energy balance on a non-reacting pellet (Appendix C) suggests that the center of a pellet heated up to $95 \%$ of the reactor temperature in about 20 seconds, significantly less than the overall reduction time (see 4.3).Inspection of pellets after reaction indicated that pellets retained their shape throughout the experiment due to excess carbon. Experimental results are tabulated in Appendix A.

\subsection{Pellet and CondensateAnalysis}

SEM images of $\mathrm{C} / \mathrm{MgO}$ pellets before and after reactionareshown in Figure 5. Before reaction, magnesia particles werein intimate contact with surrounding carbon, while after reaction direct contact between magnesia particles and carbon was reduced. The narrowing of the XRD peaks for MgO shown in Figure 6 indicated an increase in crystallite size after reaction, likely due to sintering. The loss of $\mathrm{C}$ and $\mathrm{MgO}$ contact was seemingly due to reaction and/or sintering. Increasing $\mathrm{C}$ and $\mathrm{MgO}$ contact has been shown
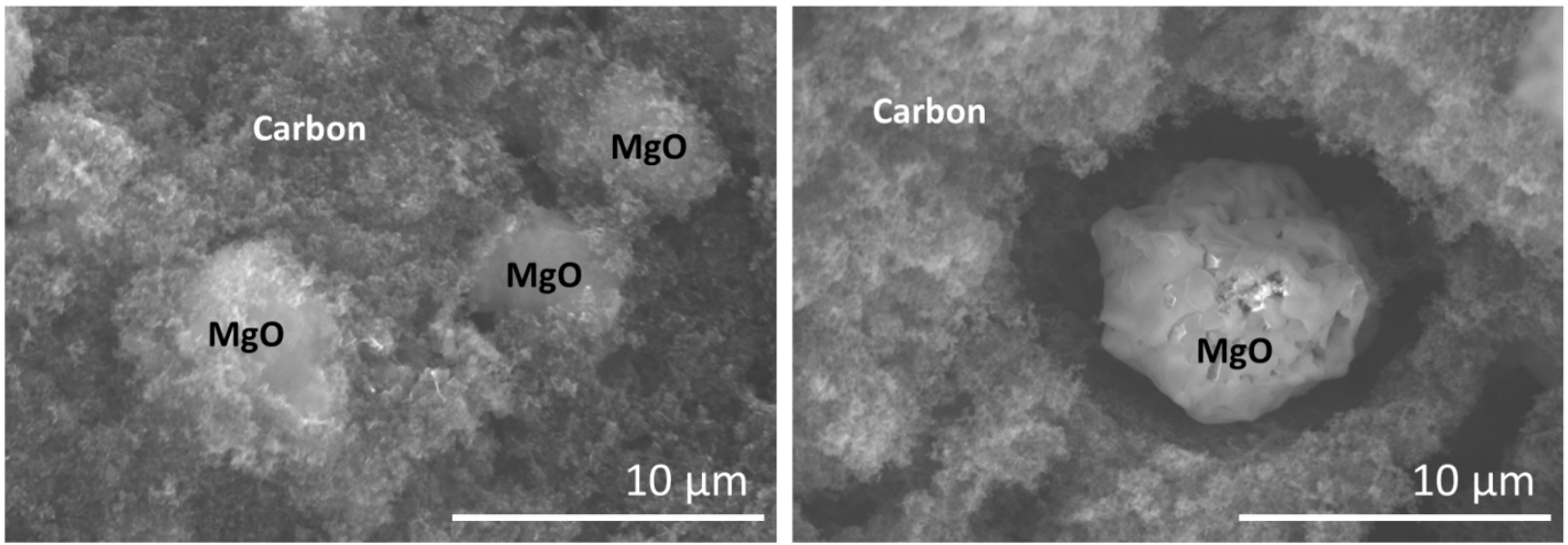

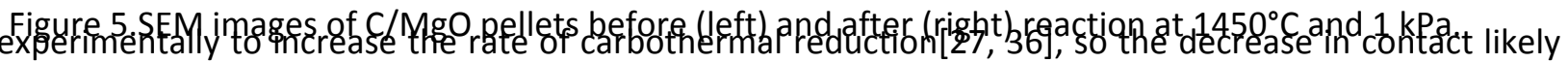

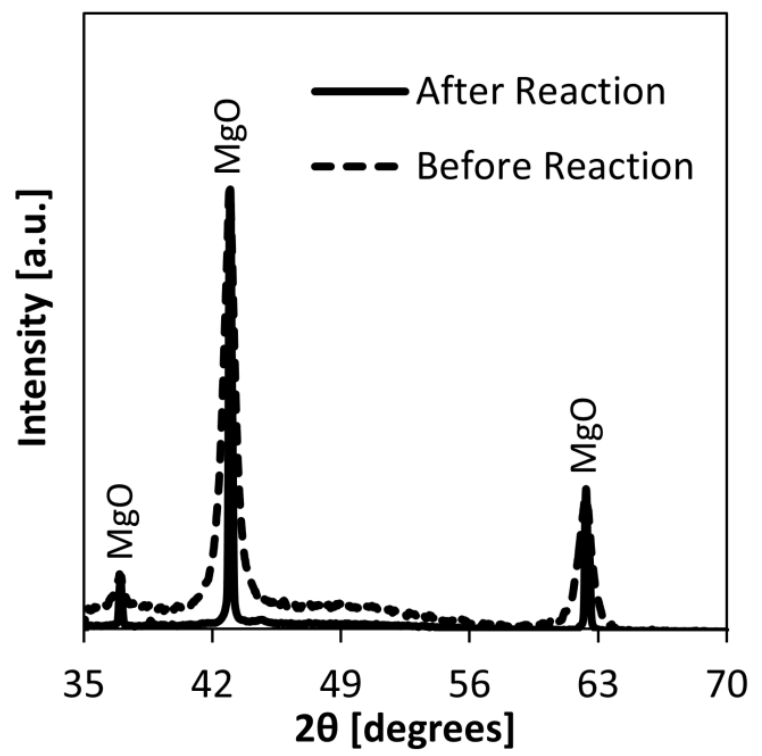

Figure 6.XRD spectra of $\mathrm{C} / \mathrm{MgO}$ pellets before and after reaction at $1450^{\circ} \mathrm{C}$ and $1 \mathrm{kPa}$

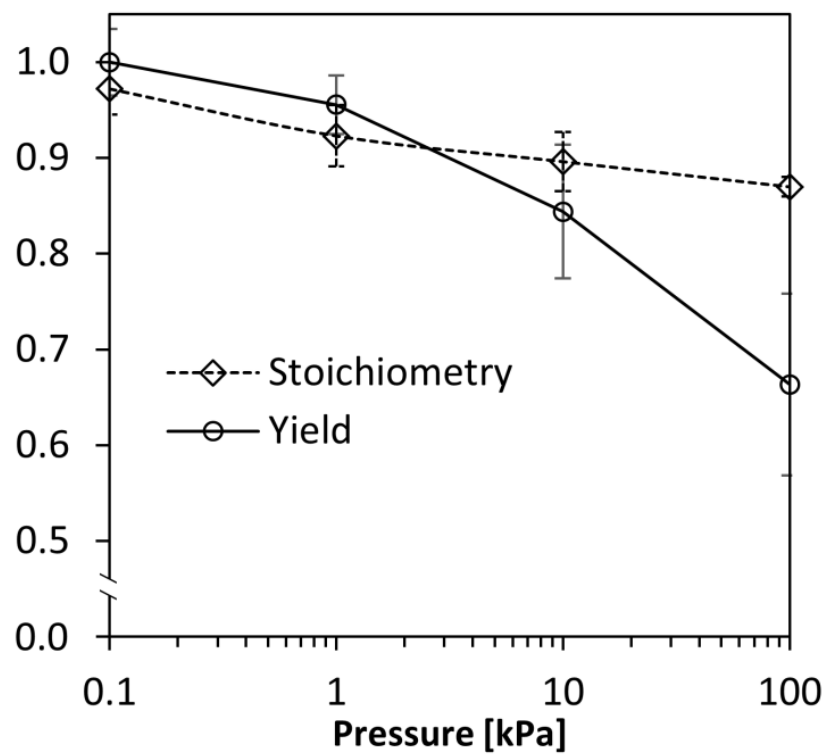

Figure 7. Reaction stoichiometry, $\lambda$, and Mg yield vs. pressure. Bars represent variation with temperature 
172 reduces the contribution of reaction (1) to the 173 overall reduction rate.Figure 7 illustrates that the 174 reaction stoichiometry, the relative amount of $C$ to 175 MgO reacted, decreased with pressure implying an 176 increase in $\mathrm{CO}_{2}$ production within the reacting 177 pellet. This suggests that the contribution of gas178 solid reactions, reactions (2) and (3), to the overall 179 reduction rate increases with pressure. Variation 180 with temperature appeared to be random, and is 181 represented by bars.Magnesium yieldcorrelated 182 well with reaction stoichiometry up to $10 \mathrm{kPa}$ 183 indicating thatthe extent of reversion is related to $184 \mathrm{CO}_{2}$ production from reaction as $\mathrm{CO}_{2}$ oxidizes $\mathrm{Mg}$ 185 more readily than $\mathrm{CO}$ [37]. With further increasing 186 pressure, some reversion must occur by CO directly 187 or indirectly through Boudouard reaction as the

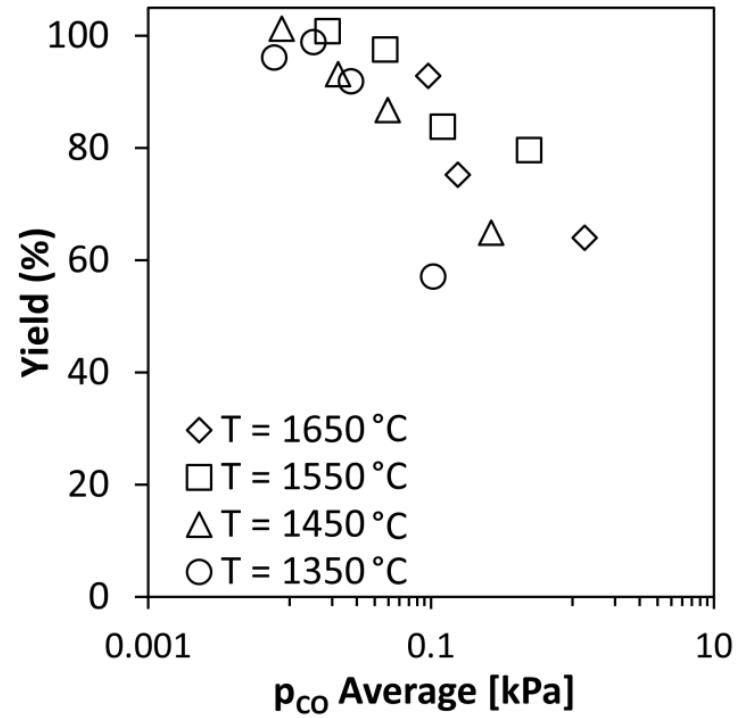

Figure $8 . \mathrm{Mg}$ yield based on the average pcoduring reaction

188 yield is less than the reaction stoichiometry.Figure 8

189 additionally illustrated that as the average CO partial pressure within the reaction chamber increases 190 the yield of magnesium decreased.

191 Condensed magnesium, Figure 9, shows columnar growth similar to magnesium produced via the 192 Pidgeon process. Magnesium oxide appears as aggregates with a dendritic structure indicative of 193 homogeneous nucleation.
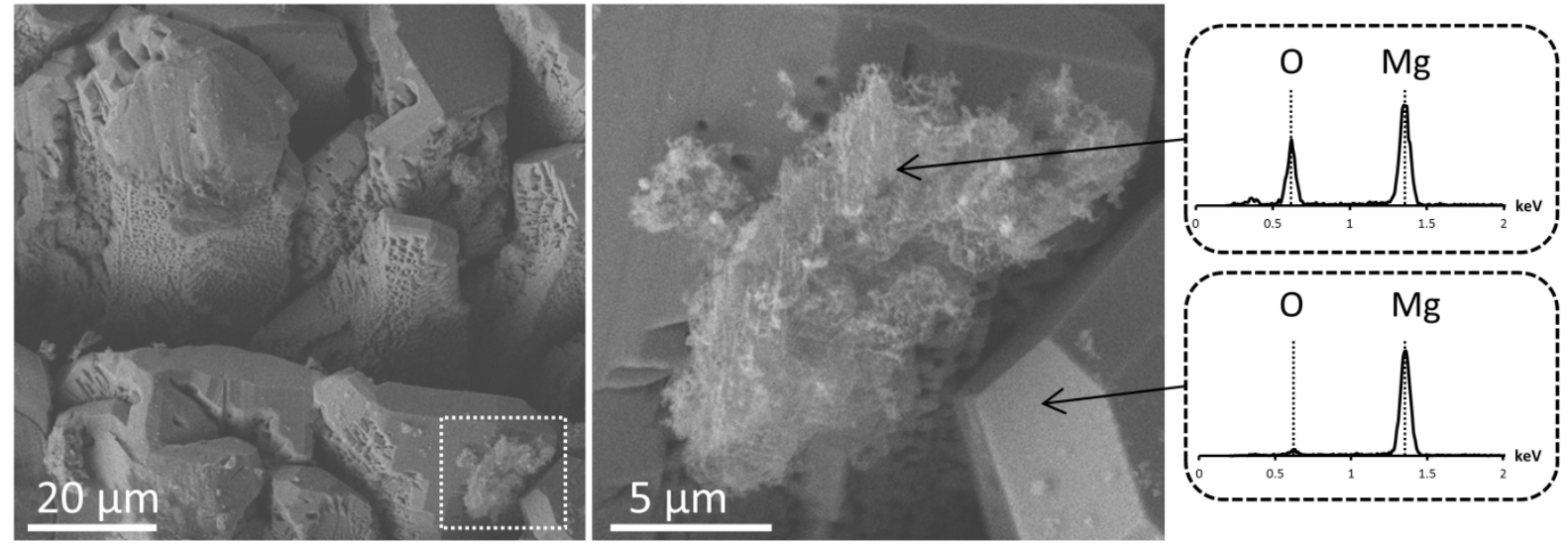

Figure 9. SEM image and EDS analysis of $\mathrm{Mg}$ and $\mathrm{MgO}$ condensate collected at a condenser temperature of $600^{\circ} \mathrm{C}$ from reaction at $1650^{\circ} \mathrm{C}$ and $0.1 \mathrm{kPa}$

\subsection{Isoconversional Analysis}

203 Isoconversional analysis was carried out using the integral method[38] to determine the change in 204 activation energy with conversion. The method originates from,

$$
\frac{d \alpha}{d t}=k(T) f(\alpha) h(P)
$$


which after integration at constant pressure and temperature,

$$
g(\alpha)=\int_{0}^{\alpha} \frac{d \alpha}{f(\alpha)}=A_{0} h(P) \int_{0}^{t} \exp \left(-\frac{E}{R T}\right) d t
$$

and rearrangement,

$$
\ln \left(t_{\alpha, i}\right)=\ln \left(\frac{g(\alpha)}{A_{0} h(P)}\right)+\frac{E_{\alpha}}{R T_{i}}
$$

resultsin the equation for analysis where $t_{\alpha, i}$ is the time required to reach conversion $\alpha$ at temperature $i$. $E(\alpha)$ can be determined by linear regression of $t_{\alpha, i}$ vs $1 / T$ at constant pressure. The integral method was used here because kinetic experiments wereassumed to be isothermal, and the integral in equation (11) can be solved analytically at constant temperature.

211 Isoconversional analysis was carried out for

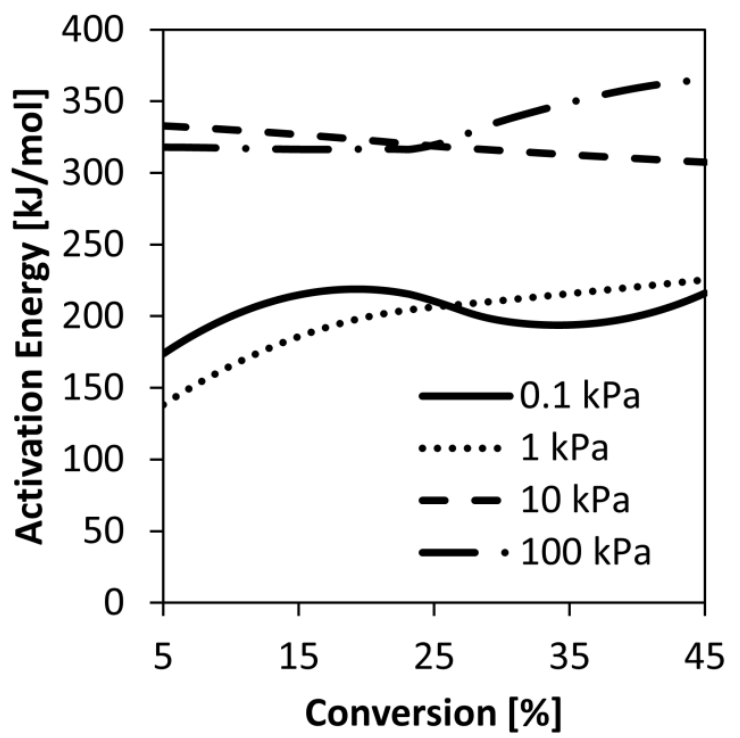

Figure 10. Isoconversional analysis by integral method at constant pressure conversions between 5 and 45\%since reactions at low temperature did not reach high conversions, and linear regression results were deemed reliable only when $t_{\alpha, l}$ was available for all four temperatures studied.

The results in Figure 10 show that activation energy is relatively constant at a given pressure, but increases significantly from 1 to $10 \mathrm{kPa}$ suggesting a change in the rate determining step. The change could result from mass transfer limitations and the influence of gas-solid reactions that become more prevalent at higher pressure, or possibly the change from a carbon limiting reaction to an $\mathrm{MgO}$ limiting reaction as the activation energy for carbon oxidation by $\mathrm{CO}_{2}$ is $\sim 200 \mathrm{~kJ} / \mathrm{mol}$ [19-23].

\subsection{Conversion as $f(T)_{P}$ and $f(P)_{T}$}

Temperature and pressure dependent conversion curves are shown in Figures 11 and 12, respectively. Gas sampling was nearly continuous $(1 \mathrm{~Hz})$ relative to the overall reduction time, however only 10 data points are shown for clarity. Model predictionsare shown as lines and will be discussed in section 5 .

The effect of temperature at constant pressure was an increase in reduction rate with increasing temperature for which the Arrhenius dependence was evaluated in the previous section. At constant temperature, pressure had a dual effect on the reduction rate. At low conversions $(\alpha<0.20)$, the reduction rate increased with decreasing system pressure, while at conversions of 0.20-0.35 a transition occurs after which the reduction rate was maximum at $10 \mathrm{kPa}$. Reduction at $100 \mathrm{kPa}$ resulted in the lowest rate for all temperatures. There exists an optimum pressure for maximum conversion within a given time interval. This phenomenon has been document previously; Gulanitzkii andChizhikov (1955)[8] 
determined that the reduction rate increased with decreasing pressure until $\approx 0.013 \mathrm{kPa}$ below which the reduction rate slowed. As system pressure only affects the diffusivity of gaseous species within the pellet and reactor, the dual effect of system pressure on the reaction rate is thought to be due primarily to mass transfer of product gases from the pellet and the decrease of $\mathrm{C}$ and $\mathrm{MgO}$ contact with conversion.

Initially, C and $\mathrm{MgO}$ contact is greatest (Figure 5) so the initial rate of reduction is likely controlled primarily by reaction (1), the solid-solid reaction of $\mathrm{C}$ with $\mathrm{MgO}$. The increase in initial reduction rate with decreasing pressure could be due to an increase in mass transfer of gaseous products out of the pellet, thus resulting in low partial pressures within the pellet that drive the reaction entropically.

As $\mathrm{C}$ and $\mathrm{MgO}$ contact decreases due to reaction and/or sintering, the rate of reaction (1) slows and the overall reduction may be propagated by gas-solid reactions. The calculated reaction stoichiometry indicates that the influence of gas-solid reactions increases with pressure. Thus, relatively high mass transfer rates, as a result of reduction at low pressures, may reduce the reduction rate by effectively sweeping $\mathrm{CO}$ and $\mathrm{CO}_{2}$ out of the pellet resulting in low partial pressures that hinder the rates of reactions (2) and (3). The overall reduction consists of two parallel but coupled reactions: gas-solid and solid-solid. In this case, the change from solid-solid dominated kinetics to gas-solid was between $0.20<\alpha<0.35$ as suggested by experimental conversion curves, $f(P)_{T}$ (Figure 12). The optimum pressure for fast kinetics is inherently dependent on the reactivity of each species as well as mixing and pellet properties. 

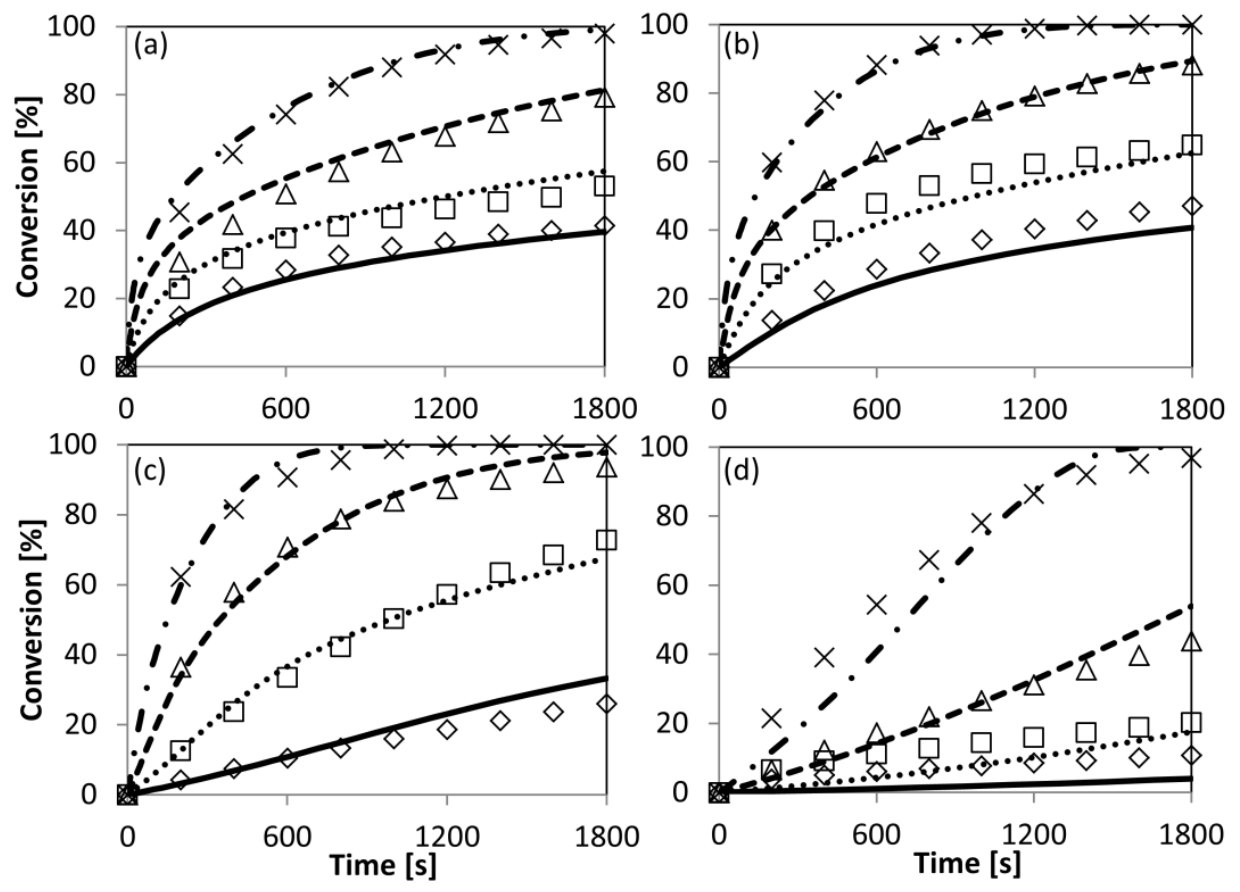

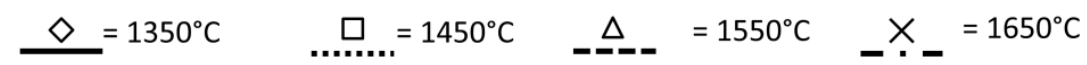

Figure 11.Temperature dependent conversion at pressures of $0.1 \mathrm{kPa}(\mathrm{a}), 1 \mathrm{kPa}(\mathrm{b}), 10 \mathrm{kPa}(\mathrm{c})$, and $100 \mathrm{kPa}$ (d).Data points represent experimental data and lines show the model fit
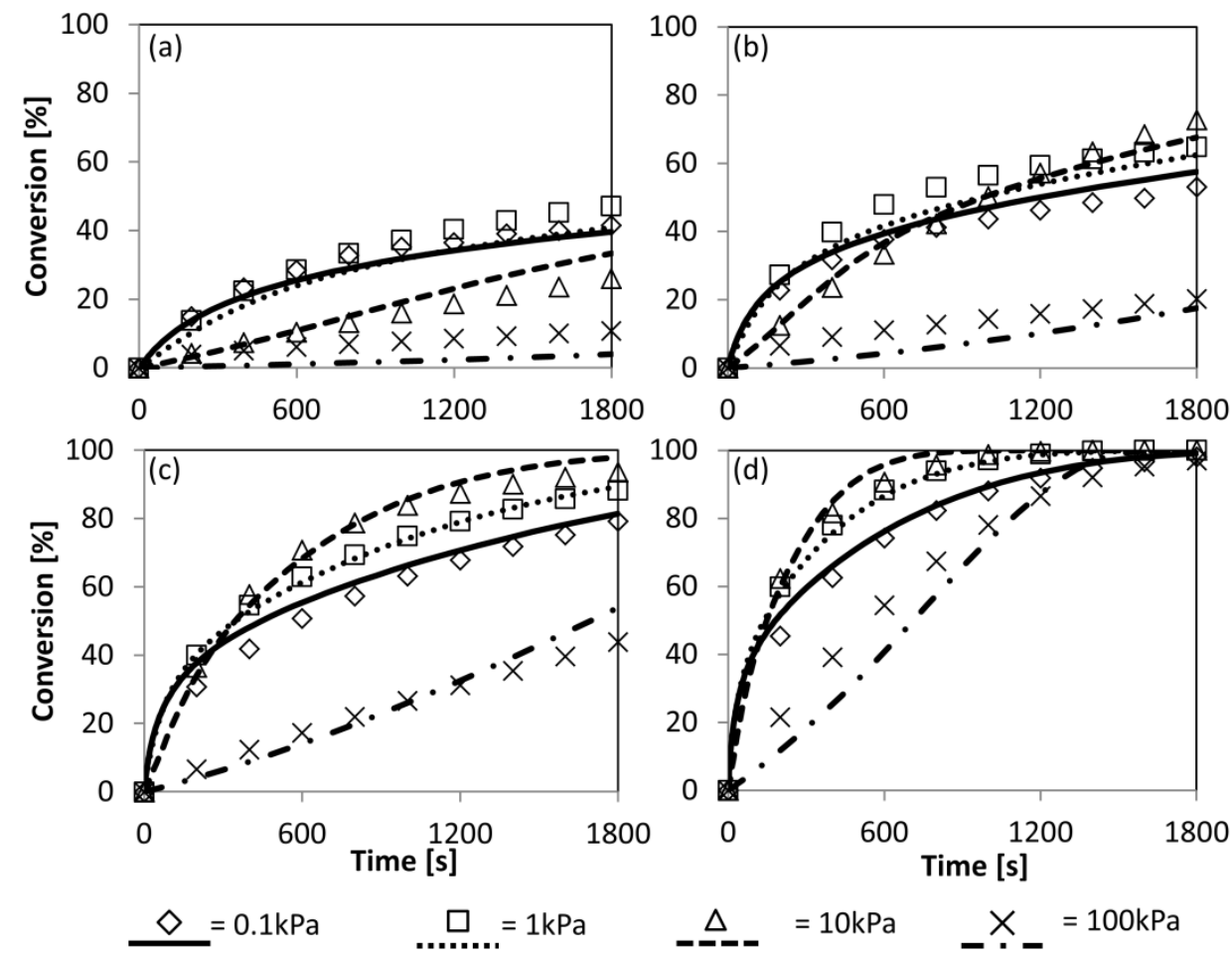

Figure 12.Pressure dependent conversion at temperatures of $1350^{\circ} \mathrm{C}$ (a) $1450^{\circ} \mathrm{C}$ (b) $1550^{\circ} \mathrm{C}$ (c) and $1650^{\circ} \mathrm{C}(\mathrm{d})$.Data points represent experimental data and lines show the model fit 262 


\section{Model Development}

where $K_{D}$ is the mass transfer coefficient at the surface of the pellet calculated using

$R_{2}$ and $R_{3}$ quantify the rates of reaction (2), $\mathrm{MgO}$ reduction by $\mathrm{CO}$, and reaction (3), $\mathrm{C}$ gasification by $\mathrm{CO}_{2}$, respectively. Carbon gasification has been studied extensively[19, 20, 22, 39-41]so the parameters for reaction (3) are taken from Turkdogan\&Vinters (1970) [19] as their results are similar to other works using relatively pure carbon $[40,41]$.

Given these rate expressions, a macroscopic species balance on a single pellet results in the following set of differential equations,

$$
\begin{gathered}
\frac{d N_{C O_{\text {Pellet }}}}{d t}=R_{1}-R_{2}+2 R_{3}-4 \pi r_{\text {pellet }}^{2} \varphi_{S} K_{d, C O}\left(C_{C O}-C_{C O_{\infty}}\right) \\
\frac{d N_{M g_{\text {Pellet }}}}{d t}=R_{1}+R_{2}-4 \pi r_{\text {pellet }}^{2} \varphi_{s} K_{d, M g}\left(C_{M g}-C_{M g_{\infty}}\right) \\
\frac{d N_{C O_{2 \text { Pellet }}}}{d t}=R_{2}-R_{3}-4 \pi r_{\text {pellet }}^{2} \varphi_{S} K_{d, C O_{2}}\left(C_{C O_{2}}-C_{C O_{2 \infty}}\right) \\
\frac{d N_{C_{P e l l e t}}}{d t}=-R_{1}-R_{3} \\
\frac{d N_{M g O_{P e l l e t}}}{d t}=-R_{1}-R_{2}
\end{gathered}
$$

279 Frössling'scorrelation[42] and $\varphi_{s}$ is the surface porosity. The partial pressures of product gases outside 280 of the reacting pellet areconsidered to be negligible; however this may not be the case in a large 281 reactor. The ideal gas law is used to relate concentration and pressure. The initial moles of $\mathrm{C}$ and $\mathrm{MgO}$ in 
a single pellet are $1.4 \cdot 10^{-3}$ and $6.4 \cdot 10^{-4}$ moles, respectively, and the initial concentrations of gases are zero.

284

285

286

287

288

289

290

291

292

293

294

295

296

297

298

299

300

301

The importance of the direct solid-solid reaction onthe overall reduction rate has been noted previously[27, 36], yet some models for carbothermal reduction of metal oxides only include the gas-solid reactions $[15,16,43]$. Here the solid-solid reaction is modeled based on a contracting area of contact.The total area of a magnesia particle is described by a shrinking core mechanism, and the area for solid-solid or gas-solid reaction is a fraction of the total area. Equations (21)-(23) describe the relation between surface area and reaction extent. The parameter $k_{p}$ describes the rate of $\mathrm{C}$ and $\mathrm{MgO}$ contact loss and $x_{p}$ describes the fraction of residual contact at high conversion. The parameter values $\left(k_{p}=7, x_{p}=0.05\right)$ are estimated from

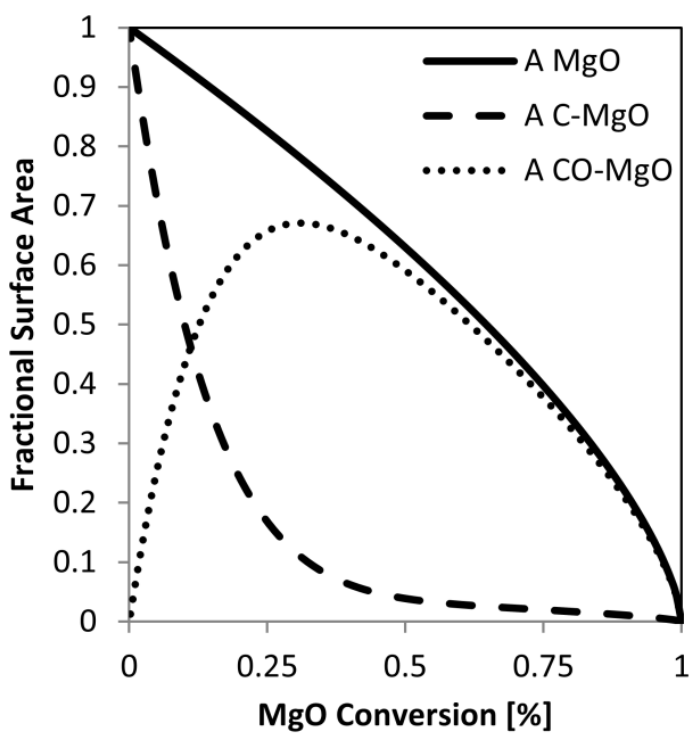

Figure 13. MgO particle surface area SEM images. At $\alpha=0.30$, the area for gas solid reaction is maximum which allows the model to predict the increased

reactivity observed at $10 \mathrm{kPa}$.

$$
\begin{gathered}
A_{M g O}=S S A_{M g O} N_{M g O}^{\frac{1}{3}} N_{M g O}^{\frac{2}{3}} \\
A_{C-M g O}=S S A_{M g O}\left(N_{M g O_{i}}^{\left(1-k_{p}\right)} N_{M g O}^{k_{p}}\left(1-x_{p}\right)+N_{M g O_{i}}^{\frac{1}{3}} N_{M g O}^{\frac{2}{3}} x_{p}\right) \\
A_{C O-M g O}=A_{M g O}-A_{C-M g O}
\end{gathered}
$$

302 The exposed surface area of carbon is assumed to not change significantly during the course of reaction 303 as the pellets were made with an excess of carbon.

$$
A_{C}=S S A_{C} N_{C_{i}}
$$

304

305

306

307

308

309

310

311

312

ADamköhler number<< 1allows for a quasi-steady-state assumption of the gas phase. That is, the partial pressures of gases change much faster than the concentration of the solids such that equilibrium partial pressures exist for a given $\mathrm{MgO}$ and $\mathrm{C}$ concentration. Equations (16)-(18) are thus reduced to algebraic expressions and can be solved analytically, reducing the system of differential equations from 5 to 2 .The analytical solution for (16)-(18) is incredibly complex and, thus, computationally expensive. A further assumption can be made that at low system pressure, the surface concentration of $\mathrm{CO}$ on $\mathrm{C}$ and $\mathrm{MgO}$ is low, therefore the reaction rate expressions given in equation (14) and (15) reduce to first order. Given this, the analytical solutions to the equilibrium partial pressures of product gases are greatly simplified and the overall reduction rate can be calculated by equation (25),

$$
\frac{d n_{M g O_{P e l l e t}}}{d t}=-k_{1} A_{C-M g O}\left(1-\frac{p_{C O_{e q}} p_{M g_{e q}}}{K_{1}}\right)-k_{2}^{\prime} A_{C O-M g O} p_{C O_{e q}}
$$


313 where $p_{C O_{e q}}$ and $p_{M g_{e q}}$ are the equilibrium partial pressure of $\mathrm{CO}$ and $\mathrm{Mg}$. The simplified model proved 314 to be valid at pressures from 0.1 to $10 \mathrm{kPa}$, but over predicted the reduction rate at $100 \mathrm{kPa}$.

Table 1. Model Parameters

\begin{tabular}{lllllll}
\hline & \multicolumn{2}{c}{ Full Model } & & \multicolumn{3}{c}{ Simplified Model } \\
\hline Parameter & $\mathrm{A}_{0}$ & & $\mathrm{E}\left[\mathrm{kJ} \cdot \mathrm{mol}^{-1}\right]$ & $\mathrm{A}_{0}$ & & $\mathrm{E}\left[\mathrm{kJ} \cdot \mathrm{mol}{ }^{-1}\right]$ \\
\hline$k_{1}$ & 14.8 & {$\left[\mathrm{~mol} \cdot \mathrm{m}^{-2} \cdot \mathrm{s}^{-1}\right]$} & 246 & 16.5 & {$\left[\mathrm{~mol} \cdot \mathrm{m}^{-2} \cdot \mathrm{s}^{-1}\right]$} & 243 \\
$k_{2}^{\prime}$ & $1.60 \cdot 10^{-4}$ & {$\left[\mathrm{~mol} \cdot \mathrm{m}^{-2} \cdot \mathrm{s}^{-1} \cdot \mathrm{Pa}^{-1}\right]$} & 187 & $4.33 \cdot 10^{-6}$ & {$\left[\mathrm{~mol} \cdot \mathrm{m}^{-2} \cdot \mathrm{s}^{-1} \cdot \mathrm{Pa}^{-1}\right]$} & 166 \\
$k_{3}^{\prime}{ }^{\prime}$ & $2.86 \cdot 10^{-1}$ & {$\left[\mathrm{~mol} \cdot \mathrm{m}^{-2} \cdot \mathrm{s}^{-1} \cdot \mathrm{Pa}^{-1}\right]$} & 243 & $2.86 \cdot 10^{-1}$ & {$\left[\mathrm{~mol} \cdot \mathrm{m}^{-2} \cdot \mathrm{s}^{-1} \cdot \mathrm{Pa}^{-1}\right]$} & 243 \\
$K_{2, c o}$ & $3.67 \cdot 10^{-3}$ & {$\left[\mathrm{~Pa}^{-1}\right]$} & -5.12 & - & & - \\
$K_{3, c o}$ & $4.35 \cdot 10^{-9}$ & {$\left[\mathrm{~Pa}^{-1}\right]$} & -137 & - & & - \\
$*$ & Parameters taken from literature $[19,40,41]$ & & & -
\end{tabular}

$316 *$ Parameters taken from literature $[19,40,41]$

317 Model parameters in Table 1 are computed by non-linear least squares minimization of the difference in 318 experimental and predicted conversion curves shown in Figures 11 and 12. The system of differential 319 equations was solved using ode15s in MatLab. The solution for gas partial pressures quickly converged 320 to equilibrium concentrations further validating a quasi-steady-state assumption. The predicted heat of 321 adsorption of $\mathrm{CO}$ on $\mathrm{MgO}$ is near the range found in literature (12.5-41.4kJ) [44, 45]. To the knowledge 322 of the authors, the reduction of $\mathrm{MgO}$ by $\mathrm{CO}$ has not been studied experimentallyso experimental and 323 predicted rate parameters cannot be compared.

324 Figure 14shows representative predicted species concentrations within the reacting pellet. As the model 325 predicts the production of $\mathrm{CO}_{2}$, the overall molar conversion of $\mathrm{MgO}$ is greater than that of $\mathrm{C}$. This 326 relative conversion is the reaction stoichiometry, $\lambda$.
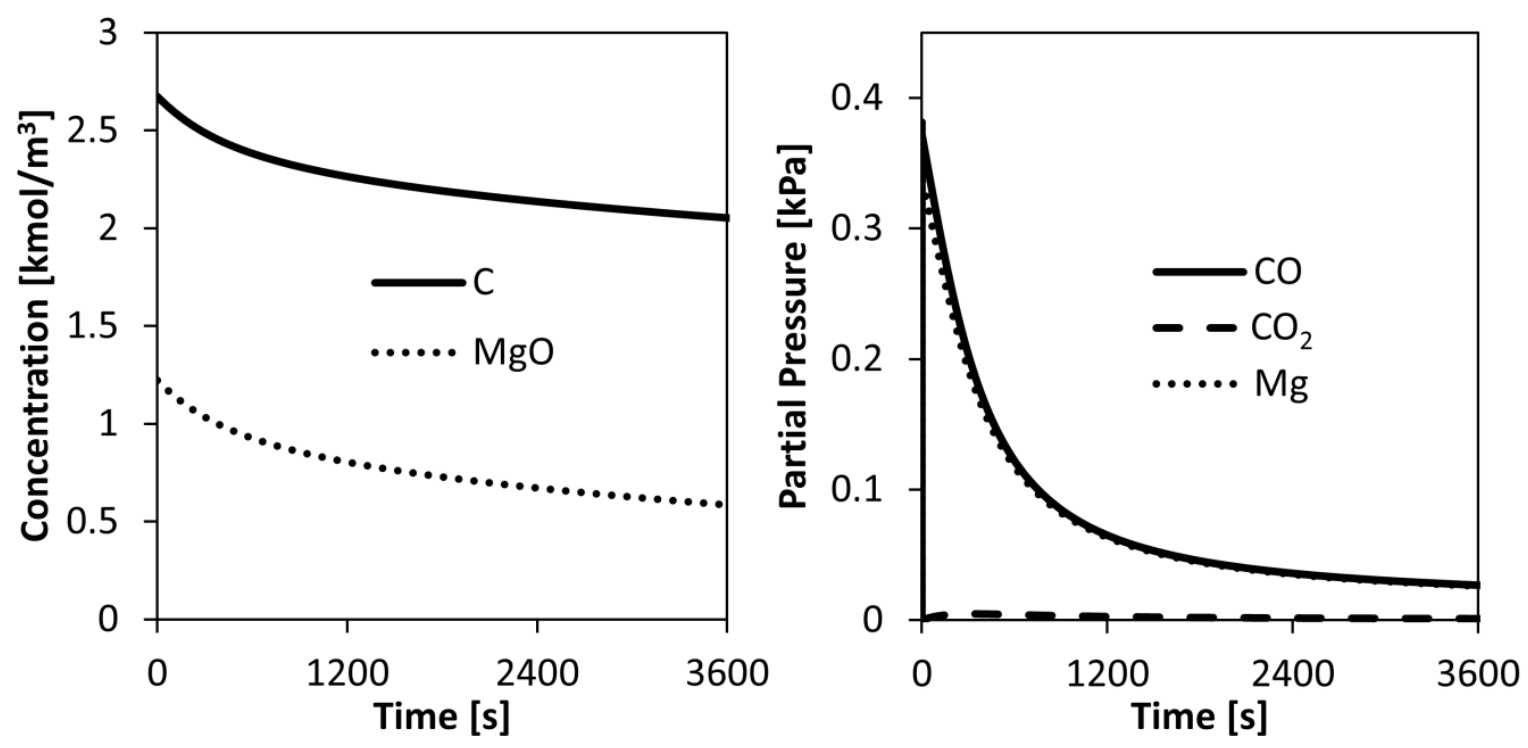

Figure 14. Model simulation at $\mathrm{T}=1350^{\circ} \mathrm{C}$ and $\mathrm{P}=1 \mathrm{kPa}$

The model represents the simplification ofa complicated system of parallel multiphase reactions coupled to diffusion and mass transfer; thus, the rate of $\mathrm{MgO}$ carbothermal reduction is dependent on the pelletization method, internal pore structure, pellet size, $\mathrm{C} / \mathrm{MgO}$ ratio as well as the particle size, grain 
size, and SSA of $\mathrm{C}$ and $\mathrm{MgO}$. Further, the addition of metals and other inorganic compounds has been shown to have pronounced catalytic effects[15, 24]. The proposed model takes some of these factors into account, and is able to describe the key phenomena in order to adequately predict the rate of $\mathrm{MgO}$ carbothermal reduction within the studied temperature and pressure range as is shown in Figures 11 and 12.A macroscopic species balance, as opposed to radial discretization, is used to reduce the number of differential equations required to represent the system kinetics, allowing the model to be implemented for scale-up calculations of pellets reacting in a moving bed or batch reactor.

Further work will be focused on measuring the intrinsic reaction rates for individual reactions (i.e. TGA for gas-solid reaction, dilatometry for SSA reduction). Independent measurement of the solid-solid reaction is extremely difficult without the interference of any gas-solid reaction.

\subsection{Conclusion}

The rate of $\mathrm{MgO}$ carbothermal reduction was studied in the range of $1350-1650^{\circ} \mathrm{C}$ and $0.1-100 \mathrm{kPa}$. Pressure was shown to have a dual effect. At conversions less than 0.20 the reduction rate increased with decreasing system pressure, while at conversions of 0.20-0.35 a transition occurred after which the reduction rate was maximum at $10 \mathrm{kPa}$. The average activation energy at different pressures was analyzed using an integral isoconversional method and revealed a change in rate-determining step between 1 and $10 \mathrm{kPa}$. The decrease in reaction stoichiometrywith pressure implied an increase in $\mathrm{CO}_{2}$ generation, and SEM imaging revealed the decrease of $\mathrm{C}$ and $\mathrm{MgO}$ contact with conversion. The evidence suggests that the importance of gas-solid reactions increases with pressure. At low conversion $(\alpha<0.20)$, the reduction rate is dominated by the direct solid-solid reaction between $\mathrm{C}$ and $\mathrm{MgO}$ resulting in an increase in reduction rate with vacuum due to low product gas partial pressures inside the pellet. As $\mathrm{C}$ and $\mathrm{MgO}$ contact degrade due to reaction and/or sintering the overall reaction must be propagated by gas-solid reactions. Relatively high mass transfer rates as a result of vacuum conditions limit the contribution of reactions (2) and (3) by removing $\mathrm{CO}$ and $\mathrm{CO}_{2}$ from the pellet. The system consists of two parallel reaction, solid-solid and gas-solid, which results in an optimum reduction pressure for maximum conversion within a given time frame. A macroscopic species balance based on reactions (1)-(3) is developed and is able to predict the reaction rate within the studied range of temperature and pressure.

\section{Acknowledgements}

The authors acknowledge the financial support from the Advanced Research Projects Agency-Energy (ARPA-E) of the US Department of Energy (DOE): Award AR0000404. 
Appendix A: Dispersion Correction

Table A1. Summary of Experimental Results

\begin{tabular}{c|c|c|c|c|c|c}
$\begin{array}{c}\text { Temperature } \\
{\left[{ }^{\circ} \mathrm{C}\right]}\end{array}$ & $\begin{array}{c}\text { Pressure } \\
{[\mathrm{kPa}]}\end{array}$ & $\begin{array}{c}\text { Reactor Flow } \\
{[\text { LPM] }}\end{array}$ & $\begin{array}{c}\text { Time } \\
{[\mathrm{s}]}\end{array}$ & $\begin{array}{c}\text { Conversion } \\
{[\%]}\end{array}$ & $\begin{array}{c}\text { Yield } \\
{[\%]}\end{array}$ & $\begin{array}{c}\text { Stoichiometry } \\
{[\lambda]}\end{array}$ \\
\hline 1350 & 0.1 & 10 & 5444 & $51.9 \pm 1.36$ & $96.1 \pm 2.36$ & $0.96 \pm 0.03$ \\
1450 & 0.1 & 10 & 8739 & $81.4 \pm 1.18$ & $100 \pm 1.14$ & $1.00 \pm 0.02$ \\
1550 & 0.1 & 10 & 6498 & $98.4 \pm 1.29$ & $100 \pm 0.95$ & $0.92 \pm 0.01$ \\
1650 & 0.1 & 10 & 3813 & $100 \pm 1.30$ & $100 \pm 0.98$ & $0.95 \pm 0.01$ \\
1350 & 1 & 10 & 6158 & $62.0 \pm 1.13$ & $98.8 \pm 1.56$ & $0.83 \pm 0.03$ \\
1450 & 1 & 10 & 4525 & $80.1 \pm 1.18$ & $93.1 \pm 1.07$ & $0.92 \pm 0.02$ \\
1550 & 1 & 10 & 3600 & $99.8 \pm 1.29$ & $97.5 \pm 0.89$ & $0.98 \pm 0.02$ \\
1650 & 1 & 10 & 3240 & $99.8 \pm 1.30$ & $92.8 \pm 0.85$ & $0.96 \pm 0.01$ \\
1350 & 10 & 10 & 5084 & $55.0 \pm 1.59$ & $91.9 \pm 2.52$ & $0.79 \pm 0.03$ \\
1450 & 10 & 10 & 4135 & $92.2 \pm 1.26$ & $86.7 \pm 0.88$ & $0.84 \pm 0.01$ \\
1550 & 10 & 10 & 3927 & $99.9 \pm 1.29$ & $83.8 \pm 0.77$ & $0.91 \pm 0.02$ \\
1650 & 10 & 10 & 1400 & $99.9 \pm 1.29$ & $75.2 \pm 1.00$ & $0.94 \pm 0.01$ \\
1650 & 10 & 10 & 1415 & $99.9 \pm 1.29$ & $86.9 \pm 0.80$ & $0.95 \pm 0.01$ \\
1350 & 100 & 1 & 8699 & $30.6 \pm 3.12$ & $57.0 \pm 5.57$ & $0.53 \pm 0.05$ \\
1450 & 100 & 1 & 8553 & $64.9 \pm 3.47$ & $64.9 \pm 2.86$ & $0.86 \pm 0.04$ \\
1550 & 100 & 1 & 7461 & $99.7 \pm 4.10$ & $79.6 \pm 2.32$ & $0.89 \pm 0.03$ \\
1650 & 100 & 1 & 2995 & $99.8 \pm 4.10$ & $63.9 \pm 1.86$ & $0.86 \pm 0.03$
\end{tabular}

371 The diffusivity of gaseous products is calculated based on kinetic theory. The binary diffusivity is 372 calculated with respect to the carrier gas, argon.

$$
\mathfrak{D}_{A B}=\frac{2}{3} \sqrt{\frac{k_{B} T}{\pi}} \sqrt{\frac{1}{2}\left(\frac{1}{m_{A}}+\frac{1}{m_{B}}\right)} \frac{1}{\pi\left(\frac{1}{2}\left(d_{A}+d_{B}\right)\right)^{2}} \frac{1}{n}
$$

373 The viscosity of the gas is estimated to be that of argon at the reaction conditions using the Sutherland 374 correlation[46].

375 For argon, $\mu_{0}=2.13 \cdot 10^{-5} \mathrm{~kg} \mathrm{~m}^{-1} \mathrm{~s}^{-1}$ and $C=144.4 \mathrm{~K}$.

$$
\mu=\mu_{0} \frac{T_{0}+C}{T+C}\left(\frac{T}{T_{0}}\right)^{3 / 2}
$$

376 The mass transfer coefficient is calculated using the Frösslingcorrelation. Gas velocityis estimated based 377 on flow through the graphite plug, essentially a $2.5 \mathrm{~cm}$ diameterpipe. 


$$
S h=2+0.552 R e^{1 / 2} S c^{1 / 3}
$$

378 The values of thermodynamic functions were estimated using FactSage. Within the temperature range 379 studied, the values of $\Delta \mathrm{H}^{\circ}$ and $\Delta \mathrm{S}^{\circ}$ were assumed to be constant. $\Delta \mathrm{H}^{\circ}=614.18 \mathrm{~kJ} \mathrm{~mol}^{-1}$ and $\Delta \mathrm{S}^{\circ}=290.06 \mathrm{~J}$ $380 \mathrm{~mol}^{-1} \mathrm{~K}^{-1}$.

381

$$
\Delta G^{\circ}=\Delta H^{\circ}-T \Delta S^{\circ}
$$

$$
K e q=\exp \left(\frac{-\Delta G^{\circ}}{R T}\right)
$$

382

383

385

$$
\begin{gathered}
T(t=0, r)=300 K \\
\left.k_{e f f} \frac{\partial T}{\partial t}\right|_{t, r=R_{p}}=\varepsilon \sigma\left(T_{W}-T\left(t, r=R_{p}\right)\right)^{4}+h\left(T_{W}-T\left(t, r=R_{p}\right)\right) \\
\left.\frac{\partial T}{\partial r}\right|_{t, r=0}=0
\end{gathered}
$$

The heat transfer coefficient is calculated based on an analogous correlation to mass transfer[47].

$$
N u=2+0.6 \operatorname{Re}^{1 / 2} \operatorname{Pr}^{1 / 3}
$$

\section{Appendix D: Dispersion Correction}

For tracer gas measurements, the reactor was brought to reaction conditions using the same methods previously described, after which a step in CO flow was introduced at the reactor inlet. The dispersed gas signal was quantified by fitting parameters $\tau_{1-n}$ in equations $[34,35]$.

$$
\begin{gathered}
\tau_{1} \frac{d C_{1}}{d t}=C_{i n}-C_{1} \\
\vdots \\
\tau_{n} \frac{d C_{n}}{d t}=C_{n-1}-C_{n}
\end{gathered}
$$

391 For the case of tracer gas measurements, $C_{\text {in }}$ is the tracer gas flow defined by,

$$
C_{i n}=\frac{C_{\max }}{2}\left(1+\tanh \left(k_{M F C}(t-\theta)\right)\right)
$$


392 where $k_{M F C}$ was determined to be $6.7 \mathrm{~s}^{-1}$ by fitting the valve response upon set point change in an MKS 393 mass flow controller. Three CSTRs in series, $n=3$, was determined to be adequate for quantifying 394 dispersion $\left(R^{2}>0.998\right)$.

395 For carbothermal reduction, $C_{i n}$ is the $\mathrm{CO}$ concentration generated by $\mathrm{C} / \mathrm{MgO}$ pellets within the reactor, 396 and $C_{3}$ is the measured concentration. By the measurement of $C O$ concentration, $C_{3}$, and numerical 397 approximations of $C_{3}{ }^{\prime}, C_{2}{ }^{\prime}$, and $C_{1}{ }^{\prime}$ one can calculate the concentration of $\mathrm{CO}$ within the reaction, $C_{i n}$.

398

399

400

401

402

403

404

405

406

407

408

409

410

411

412

413

414

415

416

417 


\begin{tabular}{|c|c|}
\hline$\lambda:$ & Overall reaction stoichiometry \\
\hline$\alpha:$ & Conversion of $\mathrm{MgO}$ to $\mathrm{Mg}_{(\mathrm{v})}$ \\
\hline$N:$ & [mole] \\
\hline$\dot{N}:$ & Molar flow $\left[\mathrm{mole} \mathrm{s}^{-1}\right.$ ] \\
\hline$Y:$ & Yield of $\mathrm{Mg}_{(\mathrm{s})}$ from $\mathrm{Mg}_{(\mathrm{v})}$ \\
\hline$\beta:$ & Reversion Coefficient \\
\hline$\tau:$ & CSTR space-time $[\mathrm{s}]$ \\
\hline$C:$ & Concentration [mole $\mathrm{m}^{-3}$ ] \\
\hline$k_{M F C}:$ & Mass flow controller response constant $\left[\mathrm{s}^{-1}\right]$ \\
\hline$\Theta:$ & Time delay $[\mathrm{s}]$ \\
\hline$R_{i}:$ & Rate of reaction i [mole $\mathrm{s}^{-1}$ ] \\
\hline$k_{i}:$ & Rate constant of reaction i [mole $\mathrm{m}^{-2} \mathrm{~s}^{-1}$ ] \\
\hline$k_{i}^{\prime}:$ & Effective rate constant of reaction i $\left[\mathrm{mol} \cdot \mathrm{m}^{-2} \cdot \mathrm{s}^{-1} \cdot \mathrm{Pa}^{-1}\right]$ \\
\hline$p_{i}:$ & Partial pressure of component i [Pa] \\
\hline$K_{i}:$ & Equilibrium constant of reaction $\mathrm{i}$ \\
\hline$K_{i, j}:$ & Equilibrium adsorption constant for reaction $\mathrm{i}$, component $\mathrm{j}\left[\mathrm{Pa}^{-1}\right]$ \\
\hline$A:$ & Surface area $\left[\mathrm{m}^{2}\right]$ \\
\hline$K_{d}:$ & Mass transfer coefficient $\left[\mathrm{m} \mathrm{s}^{-1}\right]$ \\
\hline$x_{P}:$ & Fraction of surface area decay by shrinking core $=0.05$ \\
\hline$k_{p}:$ & Surface area power decay coefficient $=7$ \\
\hline$A_{0}:$ & Pre-exponential $\left[\mathrm{mol} \mathrm{m}^{-2} \mathrm{~s}^{-1}\right]$ or $\left[\mathrm{mol} \mathrm{s}^{-1}\right]$ \\
\hline$E:$ & Activation energy $\left[\mathrm{kJ} \mathrm{mol}{ }^{-1}\right]$ \\
\hline$E_{\alpha}:$ & Activation energy at conversion $\alpha\left[\mathrm{kJ} \mathrm{mol}^{-1}\right]$ \\
\hline $\mathfrak{D}_{A B}:$ & Binary gas diffusivity of $A$ in $B\left[\mathrm{~mol} \mathrm{~m}^{-1} \mathrm{~s}^{-1}\right]$ \\
\hline$\varphi:$ & Pellet porosity $=0.4$ \\
\hline$\varphi_{s}:$ & Pellet surface porosity $=0.05$ \\
\hline$R_{p}:$ & Pellet radius $5 \cdot 10^{-3}[\mathrm{~m}]$ \\
\hline$\mu:$ & Gas viscosity $\left[\mathrm{kg} \mathrm{m}^{-1} \mathrm{~s}^{-1}\right]$ \\
\hline$\mu_{\infty}:$ & External gas viscosity $\left[\mathrm{kg} \mathrm{m}^{-1} \mathrm{~s}^{-1}\right]$ \\
\hline$\mu_{0}:$ & Argon reference viscosity $=2.13 \cdot 10^{-5}\left[\mathrm{~kg} \mathrm{~m}^{-1} \mathrm{~s}^{-1}\right]$ \\
\hline$T_{0}:$ & Reference temperature $=273.15[\mathrm{~K}]$ \\
\hline$C:$ & Sutherland constant for argon $=144.4[\mathrm{~K}]$ \\
\hline$D_{p}:$ & Average particle diameter [m] \\
\hline $\mathrm{C} / \mathrm{MgO}:$ & Carbon to magnesium oxide molar ratio \\
\hline$k_{M F C}:$ & Mass flow controller response constant $=6.7\left[\mathrm{~s}^{-1}\right]$ \\
\hline$\rho:$ & Porous pellet density $=650\left[\mathrm{~kg} \mathrm{~m}^{-3}\right]$ \\
\hline$C_{p}:$ & Average pellet specific heat $=839\left[\mathrm{~J} \mathrm{~kg}^{-1} \mathrm{~K}^{-1}\right]$ \\
\hline$k_{\text {eff: }}$ & Porous pellet thermal conductivity $=0.27\left[\mathrm{~J} \mathrm{~m}^{-1} \mathrm{~K}^{-1} \mathrm{~s}^{-1}\right]$ \\
\hline$S S A_{M g O}:$ & Magnesium oxide specific surface area $=5965\left[\mathrm{~m}^{2} \mathrm{~mol}^{-1}\right]$ \\
\hline$S S A_{C}:$ & Carbon black specific surface area $=1025\left[\mathrm{~m}^{2} \mathrm{~mol}^{-1}\right]$ \\
\hline$N_{M g O_{i}}:$ & Initial moles of $\mathrm{MgO}$ in a pellet $=6.4 \cdot 10^{-4}$ [moles] \\
\hline$N_{C_{i}}:$ & Initial moles of $\mathrm{C}$ in a pellet $=1.4 \cdot 10^{-3}$ [moles] \\
\hline$\Delta G:$ & Change in Gibbs free energy from reaction $\left[\mathrm{J} \mathrm{mol}^{-1}\right]$ \\
\hline$f(\alpha):$ & Differential form of reaction model \\
\hline$g(\alpha):$ & Integral form of reaction model \\
\hline$h(P):$ & Pressure dependence on reaction model \\
\hline$t_{\alpha, i}:$ & Time to conversion $\alpha$ for temperature i \\
\hline$f(T)_{p}:$ & Reduction rate as a function of temperature at constant pressure \\
\hline$f(P)_{T}:$ & Reduction rate as a function of pressure at constant temperature \\
\hline
\end{tabular}




\section{References}

423 1. Ramakrishnan, S., P. Koltun, and P. Warrandale, A comparison of the greenhouse impacts of magnesium produced by electrolytic and Pidgeon processes. Essential Readings in Magnesium Technology, 2004: p. 169-174.

2. Geoffrey Brooks, S.T., Peter Witt, M.N.H. Khan, and Michael Nagle, The Carbothermic Route to Magnesium. JOM, 2006. 58(5): p. 51-55.

3. ARPA-E, Modern Electro/Thermochemical Advances in Light Metals Systems, 2013, US Department of Energy.

4. Murray, J.P., A. Steinfeld, and E.A. Fletcher, Metals, nitrides, and carbides via solar carbothermal reduction of metal oxides. Energy, 1995. 20(7): p. 695-704.

5. XIONG, L.-Z., 2, CHEN Qi-yuan1, YIN Zhou-lan1, ZHANG Ping-min1 (1. School of Chemistry and Chemical Engineering, Central South University, Changsha, Hunan 410083, China; 2. College of Chemistry and Chemical Engineering, Jishou University, Jishou, Hunan 416000, China); Vacuum Carbothermal Reduction Kinetics of Zinc Oxide Ore [J]. The Chinese Journal of Process Engineering, 2010. 1.

6. Xie, W.-d., et al., Kinetics of magnesium preparation by vacuum-assisted carbothermic reduction method. Rare Metals, 2014: p. 1-6.

7. Levêque, G. and S. Abanades, Investigation of thermal and carbothermal reduction of volatile oxides ( $\mathrm{ZnO}, \mathrm{SnO} 2, \mathrm{GeO} 2$, and $\mathrm{MgO}$ ) via solar-driven vacuum thermogravimetry for thermochemical production of solar fuels. Thermochimica acta, 2015. 605: p. 86-94.

8. Gulanitzkii, B.S. and D.M. Chizhikov, Mechanism of the Reduction of Magnesium Oxide by Carbon. Izvestiia Akademii nauk SSSR, 1955. 11: p. 13-24.

9. Gruner, L.E., Traité de métallurgie: Agents et appareils métallurgiques. Principes de la combustion. Vol. 1. 1875: Dunod.

10. L'vov, B.V., Gaseous carbide mechanism of the reduction of oxides by carbon: from a graphite furnace to a blast furnace. Spectrochimica Acta Part B: Atomic Spectroscopy, 1989. 44(12): p. 1257-1271.

11. Digonskii, S., New Methods of Metal Production from their Oxidised Compounds, 1998, Nauka, St. Petersburg.

12. Baikov, A., Reduction and oxidation of metals, 1926, Metallurg.

13. Srinivasan, N. and A. Lahiri, Studies on the reduction of hematite by carbon. Metallurgical Transactions B, 1977. 8(1): p. 175-178.

14. Rankin, W. and J. Van Deventer, The kinetics of the reduction of manganous oxide by graphite. J. S. Afr. Inst. Min. Metall., 1980. 80(7): p. 239-247.

15. Berman, A. and M. Epstein, The kinetic model for carboreduction of zinc oxide. Le Journal de Physique IV, 1999. 9(PR3): p. Pr3-319-Pr3-324.

16. Osinga, T., Heat and mass transfer in a shrinking packed bed of zinc oxide and charcoal undergoing solar carbothermal reduction, 2005, SWISS FEDERAL INSTITUTE OF TECHNOLOGY ZURICH.

17. Komarek, K., A. Coucoulas, and N. Klinger, Reactions between refractory oxides and graphite. Journal of The Electrochemical Society, 1963. 110(7): p. 783-791.

18. Hong, L., H.Y. Sohn, and M. Sano, Kinetics of carbothermic reduction of magnesia and zinc oxide by thermogravimetric analysis technique. Scandinavian journal of metallurgy, 2003. 32(3): p. 171-176. 
19. Turkdogan, E. and J. Vinters, Effect of carbon monoxide on the rate of oxidation of charcoal, graphite and coke in carbon dioxide. Carbon, 1970. 8(1): p. 39-53.

20. $\mathrm{Wu}, \mathrm{P} .-\mathrm{c}$. , The kinetics of the reaction of carbon with carbon dioxide, 1950, Massachusetts Institute of Technology.

21. Strange, J. and P. Walker, Carbon-carbon dioxide reaction: Langmuir-Hinshelwood kinetics at intermediate pressures. Carbon, 1976. 14(6): p. 345-350.

22. Ergun, S., Kinetics of the reaction of carbon with carbon dioxide. The Journal of Physical Chemistry, 1956. 60(4): p. 480-485.

23. Rao, Y. and B. Jalan, A study of the rates of carbon-carbon dioxide reaction in the temperature range 839 to 1050 C. Metallurgical Transactions, 1972. 3(9): p. 2465-2477.

24. Rongti, L., et al., Catalytic reduction of magnesia by carbon. Thermochimica acta, 2003. 398(1): p. 265-267.

25. Tian, Y., et al., Analysis of Magnesia Carbothermic Reduction Process in Vacuum. Metallurgical and Materials Transactions B, 2014. 45(5): p. 1936-1941.

26. Rongti, L., P. Wei, and M. Sano, Kinetics and mechanism of carbothermic reduction of magnesia. Metallurgical and Materials Transactions B, 2003. 34(4): p. 433-437.

27. Rongti, L., et al., Kinetics of reduction of magnesia with carbon. Thermochimica acta, 2002. 390(1): p. 145-151.

28. Galvez, M., et al., Solar hydrogen production via a two-step thermochemical process based on $\mathrm{MgO} / \mathrm{Mg}$ redox reactions-Thermodynamic and kinetic analyses. International Journal of Hydrogen Energy, 2008. 33(12): p. 2880-2890.

29. Prentice, L. and M. Nagle, Mechanism and Kinetics of Reduction of Magnesium Oxide with Carbon. Magnesium Technology, 2009. 2009: p. 35-39.

30. Schunk, L.O. and A. Steinfeld, Kinetics of the thermal dissociation of $\mathrm{ZnO}$ exposed to concentrated solar irradiation using a solar-driven thermogravimeter in the 1800-2100 K range. AIChE Journal, 2009. 55(6): p. 1497-1504.

31. Kruesi, M., et al., Solar aluminum production by vacuum carbothermal reduction of alumina-Thermodynamic and experimental analyses. Metallurgical and Materials Transactions B, 2011. 42(1): p. 254-260.

32. Khawam, A. and D.R. Flanagan, Solid-state kinetic models: basics and mathematical fundamentals. The journal of physical chemistry B, 2006. 110(35): p. 17315-17328.

33. Halmann, M., A. Frei, and A. Steinfeld, Vacuum Carbothermic Reduction of Al2O3, $\mathrm{BeO}, \mathrm{MgO}-\mathrm{CaO}$, TiO2, $\mathrm{ZrO} 2, \mathrm{HfO} 2+\mathrm{ZrO} 2, \mathrm{SiO} 2, \mathrm{SiO} 2+\mathrm{Fe} 2 \mathrm{O} 3$, and $\mathrm{GeO} 2$ to the Metals. A Thermodynamic Study. Mineral Processing and Extractive Metallurgy Review, 2011. 32(4): p. 247-266.

34. Szekely, J., Gas-solid reactions1976: Elsevier.

35. Scheffe, J.R., et al., Kinetics and mechanism of solar-thermochemical H 2 production by oxidation of a cobalt ferrite-zirconia composite. Energy \& Environmental Science, 2013. 6(3): p. 963-973.

36. Nusheh, M., et al., Effect of mechanical milling on carbothermic reduction of magnesia. ISIJ international, 2010. 50(5): p. 668-672.

37. Abbud-Madrid, A., et al., Combustion of magnesium with carbon dioxide and carbon monoxide at low gravity. Journal of Propulsion and Power, 2001. 17(4): p. 852-859.

38. Vyazovkin, S., et al., ICTAC Kinetics Committee recommendations for performing kinetic computations on thermal analysis data. Thermochimica acta, 2011. 520(1): p. 119. 
513 39. Mentser, M. and S. Ergun, Kinetics of oxygen exchange between $\mathrm{CO} 2$ and $\mathrm{CO}$ on 514 carbon. Carbon, 1967. 5(4): p. 331-337.

515 40. Gulbransen, E., K. Andrew, and F. Brassart, Reaction of graphite with carbon dioxide at 1000-1600 ${ }^{\circ} \mathrm{C}$ under flow conditions. Carbon, 1965. 2(4): p. 421-429.

41. Story, S. and R. Fruehan, Kinetics of Oxidation of Carbonaceous Materials by CO2 and H2O between $1300 \mathrm{C}$ and $1500 \mathrm{C}$. Metallurgical and Materials Transactions B, 2000. 31(1): p. 43-54.

42. Bird, R.B., W.E. Stewart, and E.N. Lightfoot, Transport phenomena2007: John Wiley \& Sons.

43. Rao, Y., A physico-chemical model for reactions between particulate solids occuring through gaseous intermediates-I. Reduction of hematite by carbon. Chemical Engineering Science, 1974. 29(6): p. 1435-1445.

44. Jian-Wei, H., et al., CO adsorption on ultrathin MgO films grown on a Mo (100) surface: an IRAS study. Surface science, 1992. 261(1): p. 164-170.

45. Spoto, G., et al., Carbon monoxide $\mathrm{MgO}$ from dispersed solids to single crystals: a review and new advances. Progress in surface science, 2004. 76(3): p. 71-146.

46. Sutherland, W., LII. The viscosity of gases and molecular force. The London, Edinburgh, and Dublin Philosophical Magazine and Journal of Science, 1893. 36(223): p. 507-531.

47. Ranz, W. and W. Marshall, Evaporation from drops. Chem. Eng. Prog, 1952. 48(3): p. 141-146. 